\title{
Comparing efficacy and safety of different doses of dexamethasone in the treatment of COVID-19: a three-arm randomized clinical trial
}

\author{
Negar Toroghi ${ }^{1} \cdot$ Ladan Abbasian $^{2} \cdot$ Anahid Nourian $^{1} \cdot$ Effat Davoudi-Monfared $^{1} \cdot$ Hossein Khalili $^{1}$ (1) . \\ Malihe Hasannezhad ${ }^{2} \cdot$ Fereshteh Ghiasvand $^{2} \cdot$ Sirous Jafari $^{2} \cdot$ Hamid Emadi-Kouchak $^{2} \cdot$ Mir Saeed Yekaninejad $^{3}$
}

Received: 19 August 2021 / Revised: 18 November 2021 / Accepted: 19 November 2021 / Published online: 27 November 2021

(c) The Author(s) under exclusive licence to Maj Institute of Pharmacology Polish Academy of Sciences 2021

\begin{abstract}
Background and objectives Corticosteroids are commonly used in the treatment of hospitalized patients with COVID-19. The goals of the present study were to compare the efficacy and safety of different doses of dexamethasone in the treatment of patients with a diagnosis of moderate to severe COVID- 19.

Methods Hospitalized patients with a diagnosis of moderate to severe COVID-19 were assigned to intravenous low-dose ( $8 \mathrm{mg}$ once daily), intermediate-dose ( $8 \mathrm{mg}$ twice daily) or high-dose ( $8 \mathrm{mg}$ thrice daily) dexamethasone for up to 10 days or until hospital discharge. Clinical response, 60-day survival and adverse effects were the main outcomes of the study.

Results In the competing risk survival analysis, patients in the low-dose group had a higher clinical response than the highdose group when considering death as a competing risk ( $\mathrm{HR}=2.03,95 \% \mathrm{CI}: 1.23-3.33, p=0.03)$. Also, the survival was significantly longer in the low-dose group than the high-dose group $(\mathrm{HR}=0.36,95 \% \mathrm{CI}=0.15-0.83, p=0.02)$. Leukocytosis and hyperglycemia were the most common side effects of dexamethasone. Although the incidence was not significantly different between the groups, some adverse effects were numerically higher in the intermediate-dose and high-dose groups than in the low-dose group.

Conclusions Higher doses of dexamethasone not only failed to improve efficacy but also resulted in an increase in the number of adverse events and worsen survival in hospitalized patients with moderate to severe COVID-19 compared to the low-dose dexamethasone. (IRCT20100228003449N31).
\end{abstract}

Keywords COVID-19 $\cdot$ Dexamethasone $\cdot$ High-dose $\cdot$ Intermediate-dose $\cdot$ Low-dose

Negar Toroghi and Ladan Abbasian both as first authors.

Hossein Khalili

Khalilih@sina.tums.ac.ir; khalilih@tums.ac.ir

Negar Toroghi

negar.torjaf@yahoo.com

Ladan Abbasian

la.abbasian@gmail.com

Anahid Nourian

anahid.nouriam@gmail.com

Effat Davoudi-Monfared

edavudimonfared@gmail.com

Malihe Hasannezhad

malihehasannezhad@yahoo.com

Fereshteh Ghiasvand

ghiasvand_62@yahoo.com

Sirous Jafari

jafari_sirous@yahoo.com
Hamid Emadi-Kouchak

dr_emady@yahoo.com

Mir Saeed Yekaninejad

yekaninejad@yahoo.com

1 Department of Clinical Pharmacy, International Campus, School of Pharmacy, Tehran University of Medical Sciences, P.O.Box: 14155/6451, 1417614411 Tehran, Iran

2 Department of Infectious Diseases, Imam Khomeini Hospital Complex, Tehran University of Medical Sciences, Tehran, Iran

3 Department of Epidemiology and Biostatistics, School of Public Health, Tehran University of Medical Sciences, Tehran, Iran 


\section{Background}

Since late 2019, cumulative deaths of Coronavirus Disease 2019 (COVID-19) reached 5 million [1]. Although several worldwide and regional therapies were initially promising, most were abandoned due to minimal efficacy or safety concerns [2]. COVID-19 is a pending issue for governments and healthcare systems.

The symptoms were first recognized as cough, fever, dyspnea, sore throat, malaise, headache, and other influenza-like presentations [3]. However, acute respiratory distress syndrome (ARDS) and organ failure are common in severe and critical cases $[4,5]$.

The race for effective therapies of COVID-19 has started since the first days of the pandemic. However, few treatment options are currently available [6]. Medications like hydroxychloroquine, protease inhibitors and interferons were considered efficacious according to initial experiences but were later withdrawn from protocols due to lack of efficacy and risk of adverse effects [2,7]. Two drugs with promising results in hospitalized patients are remdesivir and dexamethasone [8,9].

Corticosteroid therapy was initially proposed for the treatment of SARS (severe acute respiratory syndrome) and MERS (Middle East Respiratory Syndrome) caused by coronaviruses like SARS-CoV-2 [10]. The rationale for corticosteroid therapy is to subside the cytokine storm in the progressive phase of COVID-19 [11].

Observational studies showed conflicting results about the efficacy of low-dose of corticosteroids in the management of COVID-19 [12, 13]. However, in RECOVERY trial, low-dose dexamethasone decreased mortality in hospitalized patients who required supplemental oxygen [8]. In another clinical trial, high-dose methylprednisolone implemented as pulse therapy decreased mortality in hospitalized patients with severe COVID-19 [14]. Considering pros and cons of corticosteroid therapy in viral infections, the optimal dose of corticosteroids in the treatment of COVID-19 is unknown. The goals of the present study were to compare the efficacy and safety of different doses of dexamethasone in the treatment of hospitalized patients with moderate to severe COVID-19.

\section{Methods}

\section{Study design}

This three-arm randomized clinical trial was conducted in Imam Khomeini Hospital Complex, a referral teaching center affiliated to Tehran University of Medical
Sciences, Tehran, Iran. The first patient was recruited at 26 October 2020 and the last one finished the intervention at 25 January 2021. The Ethics Committee of Tehran University of Medical Sciences approved the study (reference number: IR.TUMS.MEDICINE.REC.1399.430). The trial was also registered (registration number: IRCT20100228003449N31).

\section{Patients}

Hospitalized adult patients (above 18 years old) with moderate to severe COVID-19 who required supplemental oxygen were enrolled. Reverse transcriptase-polymerase chain reaction (RT-PCR) of nasopharyngeal samples and a lung computed tomography (CT) scan were considered for all patients. Positive RT-PCR test or compatible lung involvement was considered for diagnosis of COVID-19. Symptoms like fever, cough, dyspnea, malaise, headache, weakness, myalgia, arthralgia, pharyngitis, anosmia, ageusia, gastrointestinal problems, chest discomfort along with the high respiratory rate, hypoxia, and hyperthermia would suggest the diagnosis of COVID-19 in the pandemic situation.

Severity of COVID-19 was defined according to the WHO interim guidance [15]. Moderate COVID-19 was considered when clinical signs of pneumonia (fever, cough, dyspnea, and high respiratory rate) were positive along with SpO2 between 90 and 93\% on room air. Severe COVID-19 was described as clinical signs of pneumonia plus respiratory rate $>30$ breaths/min or $\mathrm{SpO} 2<90 \%$ on room air.

Exclusion criteria of the study were history of allergy to corticosteroids, uncontrolled diabetes mellitus with serum glucose above $250 \mathrm{mg} / \mathrm{dL}$, active fungal or parasitic infections, closed-angle glaucoma, history of myopathy, history of corticosteroid-induced neuropsychiatric disorders, uncontrolled cardiovascular diseases like acute coronary syndrome, myocardial infarction, acute and massive thrombosis, uncontrolled hypertension (systolic blood pressure above $140 \mathrm{mmHg}$ and diastolic blood pressure above $90 \mathrm{mmHg}$ ), acute viral hepatitis, pregnancy and lactation, history of corticosteroid therapy (for more than two weeks) and patients with critical COVID-19 (condition that would require the provision of life-sustaining therapies such as mechanical ventilation or vasopressor therapy).

\section{Randomization and masking}

Eligible patients who signed the consent form of the study were randomly assigned to low-dose, intermediate-dose, or high-dose dexamethasone group in 1:1:1 ratio. The randomization was performed using the permuted block method. Block sizes of 2 and 4 were selected. According to the list of random numbers created by Excel software, the statistician designed sequentially numbered opaque envelopes and 
then delivered to the clinical investigators. The statistician was unaware of the treatment group assignment. In addition, patients and clinical providers were blind regarding the randomization process. In terms of the treatment group assignment, patients but not physicians were blind.

\section{Procedures}

Patients in the low-dose, intermediate-dose, and high-dose groups received $8 \mathrm{mg}$ once daily, $8 \mathrm{mg}$ twice daily and $8 \mathrm{mg}$ thrice daily dexamethasone as intravenous injection, respectively. Dexamethasone treatment was started within the first $24 \mathrm{~h}$ of admission and continued for up to 10 days or until hospital discharge. According to the hospital protocol, administration of antivirals, anticoagulants, antibiotics, analgesics, fluids, electrolytes, supplemental oxygen, vitamins, minerals, nutritional supports, and stress ulcer prophylaxis were the same for all patients.

All patients were assessed by a pulmonologist at the time of admission and at least once daily during the hospitalization course. In patients with mild hypoxemia ( $\mathrm{SpO} 2$ between 90 and 92\%), moderate hypoxemia ( $\mathrm{SpO} 2$ between 85 and $89 \%$ ) and severe hypoxemia (SpO2 less than 85\%), nasal cannula, simple mask and mask with reservoir bag was utilized, respectively. If the goal $(\mathrm{SpO} 2 \geq 93 \%)$ was not achieved, non-invasive positive pressure or invasive ventilation was considered. In patients with $\mathrm{PaO} 2 / \mathrm{FiO} 2$ of 200-300 and $\leq 200 \mathrm{mmHg}$, non-invasive positive pressure support and invasive mechanical ventilation was considered, respectively.

Demographic data, clinical symptoms, vital signs, laboratory data, baseline diseases, past medical history, past drug history, history of hospitalization due to COVID-19, medications, organ function, types of respiratory supports, need for ICU admission and mechanical ventilation, complications during the hospitalization course and dexamethasoneinduced adverse effects were recorded. Each patient was followed weekly by telephone calls after hospital discharge for 60 days.

Thromboembolism prophylaxis was considered for all patients according to the hospital protocol. Either subcutaneous heparin 5000 international units three times daily or subcutaneous enoxaparin $40 \mathrm{mg}$ daily was applied. In patients with body mass index $\geq 40 \mathrm{~kg} / \mathrm{m}^{2}$, heparin and enoxaparin doses were increased to 7500 international units three times daily and $60 \mathrm{mg}$ daily, respectively.

\section{Outcomes' measure}

The primary outcome of the study was time to a clinical response that was described as improvement of at least two scores in the eight-category ordinal scale of the National Institute of Health (NIH). This scale is explained in eight categories as (1) discharge, with no limitations in usual activity (2) discharge, with some limitations in usual activity (3) hospital admission without the requirement of supplemental oxygen (4) hospital admission, requiring oxygen by mask or nasal cannula (5) hospital admission requiring noninvasive ventilation or high-flow oxygen (6) intubation and mechanical ventilation (7) mechanical ventilation and additional organ support like vasopressors, Renal Replacement Therapy (RRT) or Extracorporeal Membrane Oxygenation (ECMO) and (8) death.

The secondary outcomes of the study were time to $50 \%$ decrease in serum CRP level, time to respiratory rate $\leq 20$ breaths per minute and time to peripheral oxygen saturation $\geq 93 \%$. Other endpoints were hospital readmission, need for ICU admission and mechanical ventilation, duration of hospital and ICU stay, and 60-day survival.

\section{Complications}

Complications during hospitalization including adverse effects of dexamethasone were also recorded. Acute Kidney Injury (AKI), gastrointestinal (nausea, vomiting, gastrointestinal upset, bleeding), musculoskeletal (weakness, myopathy), hepatic (rise in serum aminotransferases and bilirubin), endocrine (hyperglycemia), hematologic (leukocytosis, lymphopenia, thrombocytosis or thrombocytopenia), cardiovascular (bradycardia, cardiac arrhythmia, heart failure, hypertension, myocardial infarction, tachycardia), psychiatric and neurologic (depression, emotional lability, euphoria, headache, insomnia, malaise) as well as secondary infections and drug allergy were closely monitored. A clinical pharmacist was responsible for daily patients' monitoring regarding the adverse effects of dexamethasone. In the suspected events, patients were also assessed by relevant consultants.

Acute Kidney Injury (AKI) was described according to the KDIQO guideline [16]. Hepatic aminotransferase above three times the upper limit of normal or total bilirubin above $2 \mathrm{mg} / \mathrm{dL}$ was defined as acute hepatic injury [17]. Other side effects were leukocytosis (white blood cell count above $10,000 \mathrm{cell} / \mathrm{mm}^{3}$ ), lymphopenia (total lymphocyte count less than $1000 \mathrm{cell} / \mathrm{mm}^{3}$ ), thrombocytosis (platelet count above $400 \times 10^{9} / \mathrm{L}$ ), hypertension (raise in blood pressure in a hypertensive patient or new-onset hypertension i.e. systolic blood pressure above $140 \mathrm{mmHg}$ or diastolic blood pressure above $90 \mathrm{mmHg}$ ), hyperglycemia (blood glucose $\geq 180 \mathrm{mg}$ / $\mathrm{dL}$ ), heart failure (exacerbation of the existing heart failure or new onset heart failure), myocardial infarction according to the European Society of Cardiology (ESC) guideline [18], peripheral edema (edema in the legs or hands during hospitalization), arrhythmia, weakness (feeling of tiredness or exhausted), myopathy (generalized muscle weakness or discomfort, cramps and stiffness), myalgia (pain or discomfort 
in use of one or some muscles), agitation, anxiety, mood changes, sleep disturbance, delirium, thrombosis (according to the ESC guideline [19], oral candidiasis (oral thrush) and other secondary infections (according to microbial culture, signs and symptoms of infection or radiologic findings).

\section{Sample size calculation}

The study's sample size was estimated according to the time to clinical response. The minimum range of factor to detect the difference was defined as $\Delta$ and the standard deviation was assumed as $\sigma$. In the sample size estimation, the ratio of $\Delta / \sigma$ considered equal 1 , with $95 \%$ statistical power and $1 \%$ type 1 error rate and $10 \%$ attrition. The sample size was estimated as 48 patients in each group [20].

\section{Statistical analysis}

The numerical variables were reported as mean and standard deviation if they passed the Shapiro-Wilk test. Otherwise, the median and interquartile range (IQR) was used. Nominal variables were reported as frequencies and percentage. For comparing the numerical and nominal variables (including demographic and baseline characteristics of patients and outcomes), one-way ANOVA and Chisquare test was used, respectively.

Hazard ratio (HR) and 95\% confidence interval (CI) were calculated by the competing risk survival model for primary and secondary outcomes. Kaplan-Meier plot was used to compare survival during 60-days follow-up between three groups and HR with 95\% CI for clinical death was also calculated. The Cox proportional hazard model for survival was adjusted by age, gender and stage of the disease. The analysis of three groups was according to the intention-to-treat (ITT) method. A logistic regression model was designed for the detection of probable predictors of response to dexamethasone therapy. $p$-value of 0.05 was assumed as a significant difference in comparing groups. SPSS software (version 21.0) and Stata (version 14.0) was used for statistical analysis.

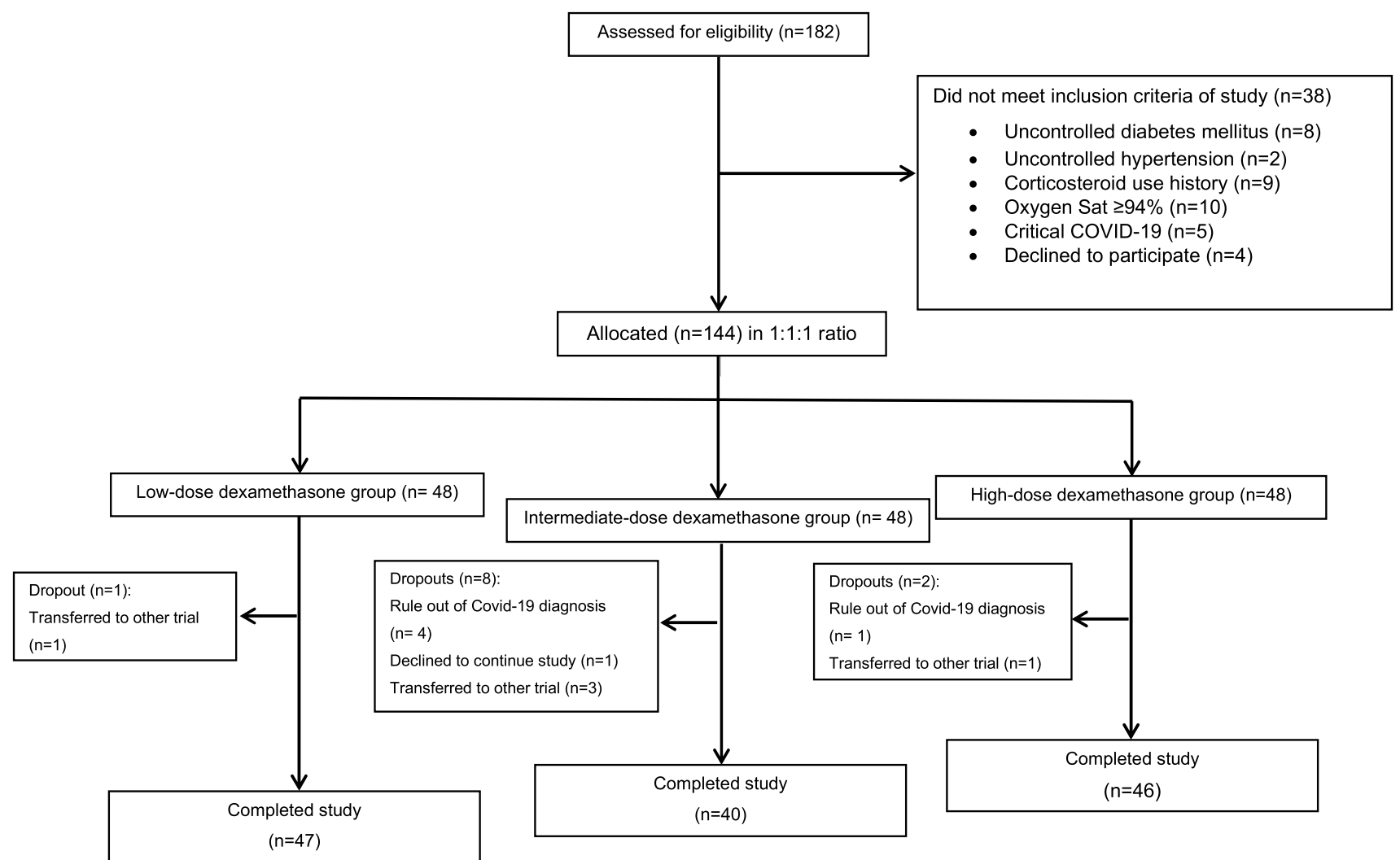

Fig. 1 Consort flow chart of the study. 144 out of 182 patients were allocated to the low-dose, intermediate-dose or high-dose group. Finally, 47 , 40 and 46 patients in the low-dose, intermediate and high-dose groups completed the study, respectively 


\section{Results}

\section{Eligibility and baseline characteristics of participants}

One-hundred forty-four patients met the inclusion criteria of the study. During the study period, 11 patients were excluded. The consort flow is shown in Fig. 1. The mean age of patients was 59 years in the low-dose and intermediate-dose groups and 56 years in the high-dose group. The diagnosis of COVID-19 was according to RTPCR test and the compatible involvements in lung CT scan in $71.4 \%$ and $28.6 \%$ of patients, respectively. The percentage of male gender was $59.6 \%, 52.5 \%$ and $58.6 \%$ in the low-dose, intermediate-dose, and high-dose groups, respectively. Hypertension, diabetes mellitus, ischemic heart disease and hypothyroidism were the most common baseline diseases. Aspirin, angiotensin receptor blockers (ARB), beta-blockers and statins were frequent medications in past drug history of patients. There was no considerable difference between the groups regarding to these characteristics (Table 1).

\section{Hospitalization course}

Cough and dyspnea were common complaints of patients at the time of hospital admission (Supplementary Table 1). Mean $\pm \mathrm{SD}$ of $\mathrm{SpO} 2$ at the time of hospital admission was $87 \pm 4 \%, 85 \pm 3 \%$ and $85 \pm 5 \%$ in the low-dose, intermediate-dose, and high-dose groups, respectively $(\mathrm{p}=0.10)$. Other vital signs and the laboratory data at the time of hospital admission are summarized (Supplementary Table 2). Concomitant with dexamethasone, patients also received other medications (Supplementary Table 3).

Types of respiratory supports at admission and during the hospitalization are addressed (Supplementary Table 4). At admission, simple face mask face and mask with reservoir bag were common modalities for oxygen supplementation. However, during the hospitalization course some patients particularly in the intermediate-dose and highdose groups became candidates for non-invasive or invasive ventilation. Estimated mean $\pm \mathrm{SD}$ of $\mathrm{PaO} 2 / \mathrm{FiO} 2$ ratio during the hospitalization course was $210 \pm 93,195 \pm 75$ and $168 \pm 69$ in the low-dose, intermediate-dose, and highdose groups, respectively $(p=0.43)$. $\mathrm{PaO} 2 / \mathrm{FiO} 2$ ratio of 300,200 and 100 was considered as mild, moderate, and severe ARDS. There was no correlation between the severity of ARDS and response to the treatment.

Course of the disease was divided into 2 phases; before and after 7 days of onset of the symptoms. At admission, the onset of the symptoms for more than 7 days was noted by $76.6 \%, 62.5 \%$ and $78.3 \%$ of patients in the low-dose, intermediate-dose, and high-dose groups, respectively. Mean \pm SD time from the onset of the symptoms to initiation of dexamethasone was $8.4 \pm 1.8,10.3 \pm 2.6$ and $9.7 \pm 2.9$ days in the low-dose, moderate-dose and highdose groups, respectively $(p=0.07)$.

Median (IQR) duration of dexamethasone therapy in the low-dose, intermediate-dose and high-dose groups was 4 $(3-6), 5(3-10)$ and $5(4-10)$ days, respectively $(p=0.14)$.

\section{Primary and secondary outcomes}

Time to clinical response was significantly different between the groups. Mean $\pm \mathrm{SD}$ days to clinical response was $4.3 \pm 1.9,5.3 \pm 2.0$ and $6.1 \pm 3.3$ in the low-dose, intermediate-dose, and high-dose groups, respectively $(p=0.02)$. In all multivariate analysis, the high-dose group was assumed as a reference group and the low-dose and intermediatedose groups were compared to this group. In competing risk survival analysis, patients in the low-dose group had more chance for a clinical response when considering death as the competing risk; for the low-dose group $(\mathrm{HR}=2.03$; $95 \%$ CI: $1.23-3.33, p=0.03$ ) and for the moderate-dose group ( $\mathrm{HR}=1.59$; 95\% CI: 0.92-2.76).

The same analysis was performed for time to decrease in serum CRP level and revealed that serum CRP level decreased faster in the intermediate-dose than the highdose group; for the low-dose group ( $\mathrm{HR}=1.5 ; 95 \% \mathrm{CI}$ : $0.75-3.00)$ and for the intermediate-dose group $(\mathrm{HR}=2.13$; 95\% CI: $1.11-3.69, p=0.04)$. In terms of time to respiratory rate $\leq 20$, there was no significant difference between the groups; for the low-dose group $(\mathrm{HR}=1.19 ; 95 \% \mathrm{CI}$ : 0.73-1.91) and for the intermediate-dose group $(\mathrm{HR}=1.08$; 95\% CI: 0.64-1.84). However, time to reach $\mathrm{SpO} 2 \geq 93 \%$ was significantly different between the groups; $(\mathrm{HR}=2.66$; 95\% CI: $1.60-4.41, p=0.03)$ for the low-dose and $(\mathrm{HR}=2.37$; 95\% CI: $1.47-3.82, p=0.01)$ for the moderatedose group. Other endpoints are shown in Table 2.

The 60-day mortality rate in the low-dose, intermediatedose, and high-dose groups were $17 \%, 30 \%$ and $41.3 \%$, respectively $(p=0.06)$. In Kaplan-Meier plot for survival time (Fig. 2) and in Cox proportional hazard model, survival was significantly longer in the low-dose than the high-dose group $(\mathrm{HR}=0.36,95 \% \mathrm{CI}=0.15-0.83, p=0.02)$. However, this was not statistically different between the intermediatedose and high-dose groups (HR $=0.7,95 \% \mathrm{CI}$ : 0.34-1.45). When the model was adjusted for age, gender and stage of the disease, the result became more significant for the lowdose group (HR $=0.30,95 \%$ CI: $0.13-0.71, p=0.006)$. The NNT (number needed to treat) was calculated, assuming the high-dose group as reference. The NNT was 4.1 for the lowdose and 8.8 for the intermediate-dose group. 
Table 1 Baseline characteristics of participants

\begin{tabular}{|c|c|c|c|c|}
\hline Parameter & $\begin{array}{l}\text { Low-dose group } \\
(n=47)\end{array}$ & $\begin{array}{l}\text { Intermediate-dose } \\
\text { group }(n=40)\end{array}$ & $\begin{array}{l}\text { High-dose group } \\
(n=46)\end{array}$ & $p$-value* \\
\hline Sex, male & 28 (59.6) & $21(52.5)$ & $31(58.6)$ & 0.44 \\
\hline Age (years) & $59 \pm 14$ & $59 \pm 17$ & $56 \pm 16$ & 0.11 \\
\hline Obesity & $9(19.1)$ & $8(20.0)$ & $11(23.9)$ & 0.56 \\
\hline Smoker & $7(14.9)$ & $3(7.5)$ & $3(6.5)$ & 0.35 \\
\hline Alcoholic & 0 & $2(5.0)$ & $1(2.2)$ & 0.22 \\
\hline Covid-19 history & $1(2.1)$ & $1(2.5)$ & 0 & 0.12 \\
\hline $\begin{array}{l}\text { History of hospitalization due to } \\
\text { COVID-19 }\end{array}$ & $1(2.1)$ & $1(2.5)$ & 0 & 0.87 \\
\hline \multicolumn{5}{|l|}{ Baseline diseases } \\
\hline Hypertension & $21(44.7)$ & $16(40.0)$ & $11(23.9)$ & 0.18 \\
\hline Diabetes Mellitus & $13(27.7)$ & $9(22.5)$ & $8(17.4)$ & 0.34 \\
\hline Ischemic heart disease & $12(25.5)$ & $5(12.5)$ & $6(13.0)$ & 0.12 \\
\hline Hypothyroidism & $4(8.5)$ & $3(7.5)$ & $6(13.0)$ & 0.90 \\
\hline Respiratory disorders & $5(10.6)$ & $1(2.5)$ & $2(4.3)$ & 0.21 \\
\hline Cerebrovascular accident & $3(6.4)$ & $3(7.5)$ & $2(4.3)$ & 0.19 \\
\hline Dyslipidemia & $2(4.3)$ & $2(5.0)$ & $4(8.7)$ & 0.15 \\
\hline Neuropsychiatric disorders & $3(6.4)$ & $5(12.5)$ & 0 & 0.56 \\
\hline Rheumatoid arthritis & $1(2.1)$ & 0 & $1(2.2)$ & 0.78 \\
\hline Parkinson's disease & $3(6.4)$ & 0 & $2(4.3)$ & 0.60 \\
\hline Depression & $3(6.4)$ & $1(2.5)$ & $1(2.2)$ & 0.39 \\
\hline Malignancy & $2(4.3)$ & 0 & $1(2.2)$ & 0.23 \\
\hline Renal disorders & $1(2.1)$ & 0 & $1(2.2)$ & 0.46 \\
\hline Liver disorders & $1(2.1)$ & 0 & 0 & 0.12 \\
\hline Heart failure & $1(2.1)$ & $1(2.5)$ & 0 & 0.98 \\
\hline \multicolumn{5}{|l|}{ Past drug history } \\
\hline Aspirin & $17(36.2)$ & $12(30.0)$ & $8(17.4)$ & 0.47 \\
\hline $\mathrm{ARB}$ & $16(34.0)$ & $10(25.0)$ & $5(10.9)$ & 0.23 \\
\hline Statin & $11(23.4)$ & $7(17.5)$ & $10(21.7)$ & 0.21 \\
\hline Beta blocker & $11(23.4)$ & $8(20.0)$ & $8(17.4)$ & 0.39 \\
\hline Metformin & $10(21.3)$ & $8(20.0)$ & $5(10.9)$ & 0.52 \\
\hline Azithromycin & $5(10.6)$ & $3(7.5)$ & $9(19.6)$ & 0.43 \\
\hline Levothyroxine & $4(8.5)$ & $3(7.5)$ & $4(8.7)$ & 0.50 \\
\hline Sofosbuvir-ledipasvir & $3(6.4)$ & $3(7.5)$ & $5(10.9)$ & 0.29 \\
\hline Insulin & $4(8.5)$ & $1(2.5)$ & 0 & 0.57 \\
\hline Doxycycline & $3(6.4)$ & $1(2.5)$ & $2(4.3)$ & 0.39 \\
\hline Hydroxychloroquine & $2(4.3)$ & $1(2.5)$ & $3(6.5)$ & 0.38 \\
\hline Immunosuppressants & $2(4.3)$ & $2(5.0)$ & $2(4.3)$ & 0.13 \\
\hline Supplements & $2(4.3)$ & $1(2.5)$ & 0 & 0.28 \\
\hline Other antibiotics & $1(2.1)$ & $2(5.0)$ & $1(2.2)$ & 0.46 \\
\hline ACEI & $1(2.1)$ & $1(2.5)$ & $1(2.2)$ & 0.55 \\
\hline
\end{tabular}

Data are presented as $n(\%)$

ACEI, Angiotensinogen Converting Enzyme Inhibitors, ARB, angiotensin receptor blockers

${ }^{*} p$-value according to one-way ANOVA or Chi-square test
The probable predictors of response to dexamethasone therapy were included in a logistic regression model. Only $\mathrm{SpO} 2$ at admission and diabetes mellitus were found to be predictive variables (Table 3).

\section{Adverse effects}

Adverse effects of dexamethasone therapy in the intermediate-dose and high-dose groups were more frequent than 
Table 2 Primary and secondary outcomes

\begin{tabular}{lllll}
\hline Parameter & $\begin{array}{l}\text { Low-dose } \\
\text { group } \\
(n=47)\end{array}$ & $\begin{array}{l}\text { Intermediate- } \\
\text { dose group } \\
(n=40)\end{array}$ & $\begin{array}{l}\text { High-dose } \\
\text { group } \\
(n=46)\end{array}$ & $p$-value* \\
\hline Time to clinical response (days) & $4.3 \pm 1.9$ & $5.3 \pm 2.0$ & $6.1 \pm 3.3$ & 0.025 \\
Time to 50\% decrease of CRP level (days) & $4.6 \pm 2.5$ & $5.3 \pm 2.4$ & $6.0 \pm 3.1$ & 0.70 \\
Time to respiratory rate $\leq$ 20 breaths/min (days) & $3.9 \pm 1.9$ & $3.1 \pm 1.8$ & $3.8 \pm 2.3$ & 0.55 \\
Time to SpO2 $\geq 93 \%$ (days) & $4.2 \pm 2.2$ & $4.9 \pm 2.7$ & $4.9 \pm 2.6$ & 0.53 \\
Need for mechanical ventilation & $3(6.4)$ & $5(12.5)$ & $6(13.0)$ & 0.51 \\
Duration of mechanical ventilation (days) & $3 \pm 2$ & $3 \pm 2$ & $4 \pm 3$ & 0.99 \\
Duration of hospital stay (days) & $5.7 \pm 3.0$ & $6.5 \pm 3.4$ & $7.0 \pm 3.6$ & 0.17 \\
Need for ICU admission & $5(10.6)$ & $5(12.5)$ & $9(19.6)$ & 0.43 \\
Duration of ICU-stay (days) & $3.2 \pm 1.5$ & $3.4 \pm 1.3$ & $5.2 \pm 3.4$ & 0.17 \\
Hospital readmission & $1(2.1)$ & $1(2.5)$ & $1(2.2)$ & 0.97 \\
60-day mortality & $8(17.0)$ & $12(30.0)$ & $19(41.3)$ & 0.06 \\
\hline
\end{tabular}

Data are presented as $n(\%)$ or mean $\pm \mathrm{SD}$

${ }^{*} p$-value according to one-way ANOVA or Chi-square test
Fig. 2 Kaplan-Meier plot for survival time. In Kaplan-Meier plot, survival was significantly longer in the low-dose than the high-dose group $p=0.02$ ). However, this was not statistically different between the intermediate-dose and highdose groups $(p=0.34)$

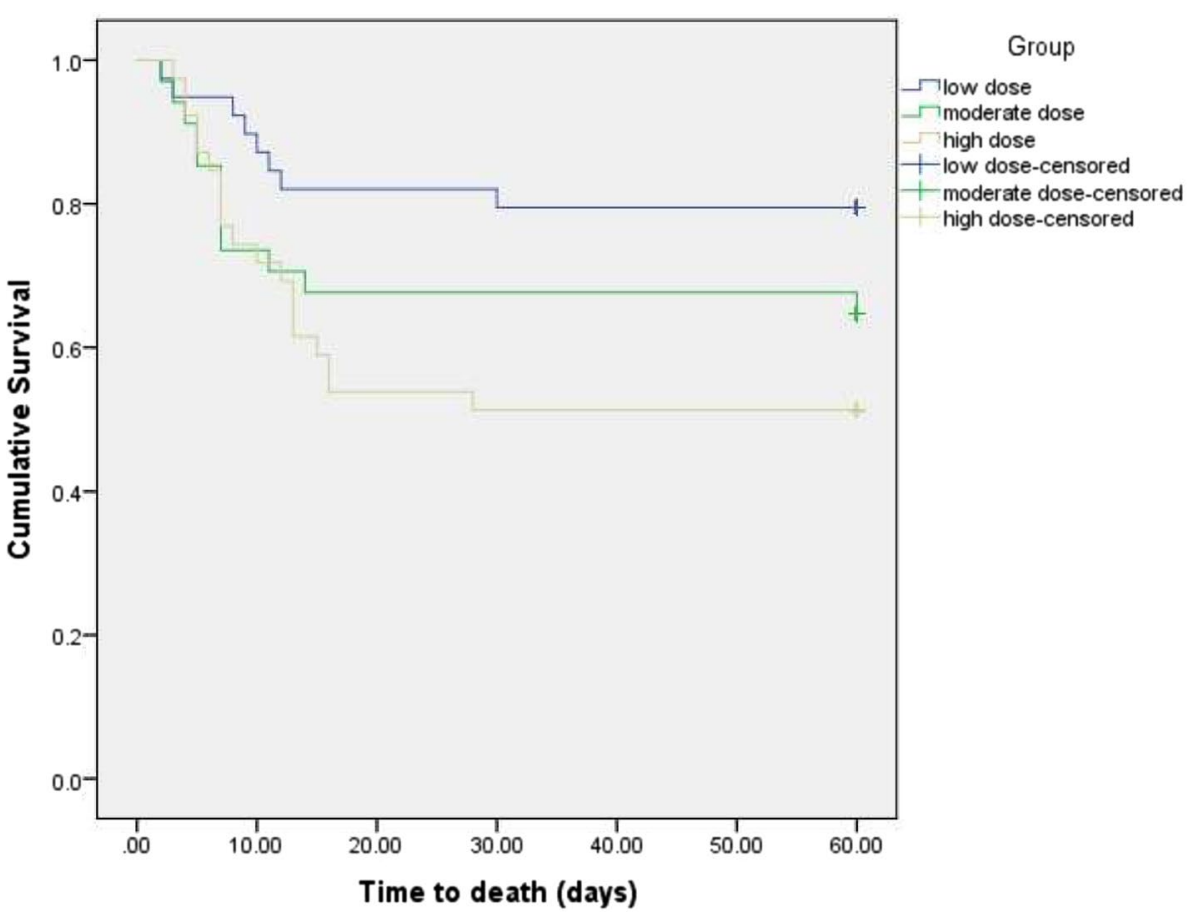

the low-dose group. However, no significant difference between the groups was detected in this regard. Leukocytosis and hyperglycemia were the most common findings. The median (IQR) dose of NPH insulin was 20.5 (17.0-28.5), 20 (16-22), and 12 (8-14) IU in the high-dose, intermediate-dose, and low-dose groups, respectively $(p=0.22)$. The median (IQR) dose of regular insulin was 15 (8-18) IU in the low-dose, 18 (15-20) IU in the intermediate-dose, and 18 (12-30) IU in the high-dose groups. There was no statistical difference between the groups, considering doses of NPH $(p=0.29)$ and regular insulin $(p=0.30)$.
Although there was no significant difference between the groups, secondary infections were more common in the high-dose group than in other groups. Bacteremia, urinary tract infection and pneumonia due to Staphylococcus aureus, E. coli and Klebsiella pneumonia, respectively, were common infections. The details of these events are shown in Table 4. 
Table 3 Probable predictors of response to dexamethasone therapy

\begin{tabular}{lccc}
\hline Variable & $p$-value* & Hazard ratio & $\begin{array}{l}95 \% \\
\text { Confidence } \\
\text { interval }\end{array}$ \\
& & & $0.67-3.45$ \\
\hline $\begin{array}{l}\text { Male sex over 70 years old } \\
\text { Baseline diseases }\end{array}$ & 0.31 & 1.52 & $1.01-6.16$ \\
Hypertension & 0.046 & 2.50 & $0.13-0.82$ \\
$\quad$ Diabetes mellitus & 0.02 & 0.33 & \\
Signs and Symptoms at the time of hospital admission & \\
Cough & 0.74 & 0.86 & $0.35-2.08$ \\
Dyspnea & 0.09 & 0.45 & $0.18-1.14$ \\
SpO2 & 0.02 & 1.10 & $1.01-1.20$ \\
Type of oxygen support & 0.13 & 1.34 & $1.11-2.66$ \\
Temperature & 0.49 & 0.80 & $0.43-1.48$ \\
Other factors & & & \\
Stage of disease (before or & 0.70 & 0.84 & $0.34-2.05$ \\
$\quad$ after 7 days of symptoms & & & \\
$\quad$ onset) & & & $0.21-1.15$ \\
Medication during hospitalization & & \\
Statin & 0.22 & 0.59 & $0.25-1.38$ \\
H-2 blockers & 0.52 & 1.58 & $0.38-6.56$ \\
Remdesivir & 0.75 & 1.15 & $0.47-2.81$ \\
Laboratory test disturbance at the time of hospital admission \\
Lymphopenia \\
\hline
\end{tabular}

* $p$-value according to the logistic regression model

\section{Discussion}

In this study, efficacy and safety of low-dose, intermediatedose and high-dose of intravenous dexamethasone in the treatment of patients with a diagnosis of moderate to severe COVID-19 were compared. Time to the clinical response was significantly shorter in the low-dose group compared to the other groups. In the survival analysis, patients in the lowdose group had a significantly higher probability of survival than the high-dose group. In addition, some adverse effects including hyperglycemia and leukocytosis were more common in the high-dose group than the other groups.

The remarkable experiences with corticosteroid therapy in former coronavirus epidemics including MERS and SARS paved the way to be included in the treatment basket of COVID-19. Therapy with high-dose corticosteroid decreased oxygen requirement and improved lung radiologic abnormalities in patients with SARS [21]. In addition, survival and hospital stay improved in these patients [22].

One of the concerns regarding corticosteroid therapy in COVID-19 is a delay in the viral clearance. This phenomenon was reported in patients with MERS [23]. However, in patients with COVID-19, the delay in SARS-CoV-2 clearance following therapy with low-dose corticosteroid has not been reported [24]. Delay in the viral clearance may be due
Table 4 Adverse events during the hospitalization course

\begin{tabular}{lllll}
\hline Parameter; $n(\%)$ & $\begin{array}{l}\text { Low-dose group } \\
(n=47)\end{array}$ & $\begin{array}{l}\text { Intermediate-dose } \\
\text { group }(n=40)\end{array}$ & $\begin{array}{l}\text { High-dose group } \\
(n=46)\end{array}$ & $p$-value* \\
\hline Acute Kidney Injury & $3(6.4)$ & 0 & $1(2.2)$ & 0.22 \\
Acute Hepatic Injury & $5(10.6)$ & $3(7.5)$ & $4(8.7)$ & 0.90 \\
Leukocytosis & $18(38.3)$ & $17(42.5)$ & $22(47.8)$ & 0.43 \\
Lymphopenia & $12(25.5)$ & $12(30.0)$ & $11(23.9)$ & 0.81 \\
Thrombocytosis & $8(17.0)$ & $4(10.0)$ & $4(8.7)$ & 0.50 \\
Arrhythmia & $6(12.8)$ & $4(10.0)$ & $11(23.9)$ & 0.11 \\
Myocardial Infarction & $2(4.3)$ & 0 & $1(2.2)$ & 0.43 \\
Raise in blood pressure & $12(25.5)$ & $15(37.5)$ & $16(34.8)$ & 0.33 \\
Peripheral Edema & $1(2.1)$ & 0 & $3(6.5)$ & 0.16 \\
Exacerbation of heart failure & $2(4.3)$ & 0 & $1(2.2)$ & 0.43 \\
Hyperglycemia & $14(29.8)$ & $15(37.5)$ & $22(47.8)$ & 0.10 \\
Mood changes & $6(12.8)$ & $8(20.0)$ & $4(8.7)$ & 0.32 \\
Anxiety & $4(8.5)$ & $5(12.5)$ & $1(2.2)$ & 0.20 \\
Delirium & $1(2.1)$ & $3(7.5)$ & 0 & 0.11 \\
Agitation & $6(12.8)$ & $5(12.5)$ & $1(2.2)$ & 0.16 \\
Sleep disturbances & $11(23.4)$ & $8(20.0)$ & $12(26.1)$ & 0.72 \\
Myopathy & $1(2.1)$ & $3(7.5)$ & $2(4.3)$ & 0.46 \\
Weakness & $5(10.6)$ & $9(22.5)$ & $6(13.0)$ & 0.25 \\
Thrombosis & 0 & 0 & $1(2.2)$ & 0.36 \\
Oral Candidiasis & $4(8.5)$ & $9(22.5)$ & $4(8.7)$ & 0.08 \\
Secondary infections & $1(2.1)$ & $1(2.5)$ & $4(8.7)$ & 0.20 \\
\hline
\end{tabular}

Data are presented as $n(\%)$

* $p$-value according to Chi-square test 
to other factors such as age and severity of the disease [25]. It seems that the effect of corticosteroid therapy on the viral clearance in COVID-19 is dose-dependent [24-27].

Corticosteroid therapy may worsen the therapy outcome in patients with COVID-19. In an observational study, although mortality was not significantly changed, more patients in the corticosteroid group progressed to the severe form of the disease. Also, corticosteroid therapy delayed the resolution of fever and viral clearance [13].

RECOVERY (Randomized Evaluation of COVID-19 Therapy) is a currently running trial looking into treatment options for coronavirus (COVID-19). In an arm of RECOVERY trial, the role of corticosteroid therapy in the treatment of COVID-19 has been examined. Low-dose dexamethasone ( $6 \mathrm{mg} /$ daily for up to 10 days) significantly reduced the duration of hospital stay and 28-day mortality in hospitalized patients with COVID-19 [8].

Corticosteroids might decrease the mortality risk in patients with moderate to severe ARDS regardless of COVID-19 [28]. This effect has been also detected in COVID-19 patients with $\mathrm{PaO} / \mathrm{FiO} 2$ ratio $<200$ at the time of hospital admission [29].

The appropriate routine, dose and duration of corticosteroid therapy for patients with COVID-19 have not been defined yet; albeit different corticosteroids with variable doses and durations were examined in patients with different disease severities.

Higher doses of corticosteroid therapy have been examined in a few studies. Corticosteroids administered at high doses improved survival and reduced the need for mechanical ventilation particularly in COVID-19 patients with severe pneumonia, respiratory failure, severe ARDS, at risk for hyper-inflammatory response and high serum levels of inflammatory biomarkers [14, 30-35]. However, most of the above-mentioned studies were retrospective. Randomized clinical trials are needed to confirm these effects. In an ongoing study (TACROVID trial), the efficacy and safety of methylprednisolone as pulse therapy (120 mg daily for three consecutive days) along with tacrolimus are targeted in patients with severe COVID-19 [36].

Low doses of corticosteroids have also been examined in patients with COVID-19. In an observational study, 40-80 mg daily methylprednisolone administered for about one week reduced mechanical ventilation requirement in patients with significant lung involvement. Secondary bacterial infections were recognized as complications of corticosteroid therapy used in this study [12]. Furthermore, in CoDEX trial, dexamethasone $20 \mathrm{mg}$ daily for 5 days, proceeded by a dose of $10 \mathrm{mg}$ daily for another 5 days or until discharge from ICU, resulted in prolonged survival and increased ventilator-free days in patients with COVID. In this trial, $31.1 \%$ and $28.4 \%$ of patients in the corticosteroid and control groups, respectively, required insulin therapy and, respectively, $21.9 \%$ and $29.1 \%$ developed secondary infections [37]. In the study of Fadel et al. administration of $0.5-1 \mathrm{mg} / \mathrm{kg} / \mathrm{day}$ methylprednisolone for 3 days at the early stage of the infection decreased mortality rate and the necessity of hospitalization [38].

Safety is the main concern of corticosteroid therapy in patients with COVID-19. Importantly, in the CoDEX trial, the incidence of adverse effects including secondary infections and hyperglycemia were not significantly different in the treatment groups indicating that the therapy is considered safe [37].

Dexamethasone, hydrocortisone and methylprednisolone are the most studied corticosteroids in the treatment of patients with COVID-19. In Ko et al., study, the survival benefit of methylprednisolone and the equivalent dose of dexamethasone was compared in mechanically ventilated patients with COVID-19. In Ko et al., study, the survival benefit of methylprednisolone and the equivalent dose of dexamethasone was compared in mechanically ventilated patients with COVID-19. It was reported that the survival rate was significantly higher in patients who received methylprednisolone than those treated with dexamethasone [39]. In another study, methylprednisolone ( $2 \mathrm{mg} / \mathrm{kg} /$ day) was significantly superior to dexamethasone in terms of improvement of the clinical status of COVID-19 patients who required respiratory support [40]. In REMAP-CAP, a study that was terminated at the early stage due to the release of the RECOVERY trial results, two regimens of hydrocortisone were compared in patients with COVID-19 who required respiratory or cardiovascular support. In both regimens hydrocortisone improved organ support-free days [41].

One of the major concerns in patients with COVID-19 are secondary infections. Co-infection is uncommon (3.1\%) but may be increased up to $4.7 \%$ during the hospitalization course [42].

Hyperglycemia is another dose-dependent adverse effect of corticosteroid therapy [43]. In our study, more patients in the high-dose dexamethasone group experienced hyperglycemia during the hospitalization course. In the RECOVERY trial, hyperglycemia, psychosis and gastrointestinal hemorrhage were detected [8].

In most studies, the time lapsed from the presentation of the symptoms and the start of corticosteroid therapy was not clearly defined [12, 37-41]. In our study, most patients received dexamethasone after 7 days from the onset of the symptoms.

Low-dose corticosteroid therapy is recommended as the standard of care for hospitalized patients with COVID-19 who require supplemental oxygen. In addition, remdesivir is recommended for hospitalized patients but not under mechanical ventilation $[44,45]$.

According to our hospital protocol, most patients received remdesivir as the antiviral regimen. Benefits of 
antiviral therapy in hospitalized patients with COVID-19 requiring supplemental oxygen are unclear. Considering design, population, stage and severity of the disease, the time of administration and concomitant medications, the main outcomes of the available studies are different. Results of a recently published large multi-center observational cohort study showed that remdesivir can improve survival if the treatment is implemented upon hospital admission [46]. However, in the DisCoVeRy trial, remdesivir did not show further clinical benefits in comparison to standard care [47].

In our study, the effect of concomitant treatments on dexamethasone response was evaluated using a logistic regression model. None of the treatments such as administration of statins, $\mathrm{H}-2$ blockers, melatonin and remdesivir was a predictor. During the study period, 11 patients were excluded. Most patients (6 out of 11) stopped the protocol due to exclusion of COVID-19 diagnosis. At the same time, patients were free to choose other ongoing trials. Attrition or Myth 2 bias (dissimilar dropout rates between study arms) is a systematic error caused by unequal loss of participants from a randomized controlled trial. Enrolled patients might withdraw the protocol of the study due to unsatisfactory efficacy, adverse events, or death [48]. To resolve this type of error, intention-to-treat (ITT) analysis was applied.

Detection of long-term complications of COVID-19 or dexamethasone (hip necrosis, post-COVID syndrome, pulmonary embolism) was not possible due to a short, 60-day follow-up.

\section{Conclusion}

To the best of our knowledge, this was the first randomized clinical trial that compared efficacy and safety of different doses of dexamethasone in patients with moderate to severe COVID-19. A similar protocol in terms of supportive care, antiviral therapy, deep vein thrombosis, and stress ulcer prophylaxis was applied for all patients. Patients were followed for 60 days. Higher doses of dexamethasone not only failed to improve efficacy but also resulted in an increase in the number of adverse events and worsen survival in hospitalized patients with moderate to severe COVID-19 compared to the low-dose dexamethasone. Therefore, based on the results of the study the low-dose dexamethasone $(8 \mathrm{mg} /$ day) can be recommended for these patients.

Supplementary Information The online version contains supplementary material available at https://doi.org/10.1007/s43440-021-00341-0.

Acknowledgements We would like to thank the nurses and other staffs of Imam Khomeini Hospital Complex for their kind supports. No grant was received regarding this work.
Authors' contributions LA: patients' assessment, editing the manuscript. NT: data gathering, Patients' assessment. AN: assessment Inclusion criteria, data gathering. ED-M: interpretation of the data, drafting the manuscript. HK: primary investigator, editing the manuscript. $\mathrm{MH}$ : patients' assessment. FG: patients' assessment. SJ: patients' assessment. HEK: patients' assessment. MSY: data analysis.

Funding The authors did not receive any funds for this work.

Availability of data and materials Available per request.

\section{Declarations}

Conflict of interest There is no conflict of interest for authors to declare.

Ethics approval The Ethics Committee of Tehran University of Medical Sciences approved the study (reference number: IR.TUMS.MEDICINE.REC.1399.430)

Consent to participate Inform consent was obtained from all participants or from a responsible first-degree family member.

Consent for publication Patients signed informed consent regarding publishing their data.

\section{References}

1. World Health Organization, COVID-19 Weekly Epidemiological Update, 11 October 2021. 2021. https://www.who.int/publicatio $\mathrm{ns} / \mathrm{m} /$ item/weekly-epidemiological-update-on-covid-19---11october-2021. Accessed 14 Oct 2021.

2. WHO Solidarity Trial Consortium. Repurposed antiviral drugs for Covid-19-Interim WHO solidarity trial results. N Engl J Med. 2021;384(6):497-511. https://doi.org/10.1056/NEJMoa2023184.

3. Wiersinga WJ, Rhodes A, Cheng AC, Peacock SJ, Prescott HC. Pathophysiology, transmission, diagnosis, and treatment of coronavirus disease 2019 (COVID-19): a review. JAMA. 2020;324(8):782-93. https://doi.org/10.1001/jama.2020.12839.

4. Gattinoni L, Chiumello D, Rossi S. COVID-19 pneumonia: ARDS or not? Crit Care. 2020;24(1):154. https://doi.org/10.1186/ s13054-020-02880-z.

5. Wang T, Du Z, Zhu F, Cao Z, An Y, Gao Y, Jiang B. Comorbidities and multi-organ injuries in the treatment of COVID-19. Lancet. 2020;395(10228): e52. https://doi.org/10.1016/S01406736(20)30558-4.

6. Salama C, Han J, Yau L, Reiss WG, Kramer B, Neidhart JD, et al. Tocilizumab in patients hospitalized with Covid-19 pneumonia. $\mathrm{N}$ Engl J Med. 2021;384(1):20-30. https://doi.org/10.1056/NEJMo a2030340.

7. RECOVERY Collaborative Group, Horby P, Mafham M, Linsell L, Bell JL, Staplin N, Emberson JR, et al. Effect of hydroxychloroquine in hospitalized patients with Covid-19. N Engl J Med. 2020;383(21):2030-40. https://doi.org/10.1056/NEJMoa2022926.

8. RECOVERY Collaborative Group, Horby P, Lim WS, Emberson JR, Mafham M, Bell JL, Linsell L, et al. Dexamethasone in hospitalized patients with Covid-19. N Engl J Med. 2021;384(8):693704. https://doi.org/10.1056/NEJMoa2021436.

9. Rubin D, Chan-Tack K, Farley J, Sherwat A. FDA approval of remdesivir-a step in the right direction. N Engl J Med. 2020;383(27):2598-600. https://doi.org/10.1056/NEJMp2032369. 
10. Lee KH, Yoon S, Jeong GH, Kim JY, Han YJ, Hong SH, et al. Efficacy of corticosteroids in patients with SARS, MERS and COVID-19: a systematic review and meta-analysis. J Clin Med. 2020;9(8):2392. https://doi.org/10.3390/jcm9082392.

11. Arabi YM, Chrousos GP, Meduri GU. The ten reasons why corticosteroid therapy reduces mortality in severe COVID-19. Intensive Care Med. 2020;46(11):2067-70. https://doi.org/10.1007/ s00134-020-06223-y.

12. Li Y, Zhou X, Li T, Chan S, Yu Y, Ai JW, et al. Corticosteroid prevents COVID-19 progression within its therapeutic window: a multicentre, proof-of-concept, observational study. Emerg Microbes Infect. 2020;9(1):1869-77. https://doi.org/10.1080/ 22221751.2020 .1807885$.

13. Ding C, Feng X, Chen Y, Yuan J, Yi P, Li Y, et al. Effect of Corticosteroid therapy on the duration of SARS-CoV-2 clearance in patients with mild COVID-19: a retrospective cohort study. Infect Dis Ther. 2020;9(4):943-52. https://doi.org/10.1007/ s40121-020-00337-y.

14. Edalatifard M, Akhtari M, Salehi M, Naderi Z, Jamshidi A, Mostafaei $S$, et al. Intravenous methylprednisolone pulse as a treatment for hospitalised severe COVID-19 patients: results from a randomised controlled clinical trial. Eur Respir J. 2020;56(6):2002808. https://doi.org/10.1183/13993003. 02808-2020.

15. World Health Organization. 2020. Clinical management of COVID-19: interim guidance, 27 May 2020. World Health Organization. https://apps.who.int/iris/handle/10665/332196.

16. Khwaja A. KDIGO clinical practice guidelines for acute kidney injury. Nephron Clin Pract. 2012;120(4):c179-84. https://doi.org/ $10.1159 / 000339789$.

17. Lescot T, Karvellas C, Beaussier M, Magder S. Acquired liver injury in the intensive care unit. Anesthesiology. 2012;117(4):898-904. https://doi.org/10.1097/ALN.0b013e3182 $66 \mathrm{c} 6 \mathrm{df}$.

18. Ibanez B, James S, Agewall S, Antunes MJ, Bucciarelli-Ducci C, Bueno H, ESC Scientific Document Group, et al. ESC Guidelines for the management of acute myocardial infarction in patients presenting with ST-segment elevation: The Task Force for the management of acute myocardial infarction in patients presenting with ST-segment elevation of the European Society of Cardiology (ESC). Eur Heart J. 2018;39(2):119-77. https://doi.org/10.1093/ eurheartj/ehx393.

19. Mazzolai L, Aboyans V, Ageno W, Agnelli G, Alatri A, Bauersachs R, et al. Diagnosis and management of acute deep vein thrombosis: a joint consensus document from the European Society of Cardiology working groups of aorta and peripheral vascular diseases and pulmonary circulation and right ventricular function. Eur Heart J. 2018;39(47):4208-18. https://doi.org/10.1093/eurhe artj/ehx003.

20. Neter J, Kutner MH, Nachtsheim CJ, et al. Applied linear statistical models. 5th Edition, McGraw-Hill, Irwin, New York; 2005.

21. Ho JC, Ooi GC, Mok TY, Chan JW, Hung I, Lam B, et al. High-dose pulse versus nonpulse corticosteroid regimens in severe acute respiratory syndrome. Am J Respir Crit Care Med. 2003;168(12):1449-56. https://doi.org/10.1164/rccm. 200306-766OC.

22. Chen RC, Tang XP, Tan SY, Liang BL, Wan ZY, Fang JQ, et al. Treatment of severe acute respiratory syndrome with glucosteroids: the Guangzhou experience. Chest. 2006;129(6):1441-52. https://doi.org/10.1378/chest.129.6.1441.

23. Arabi YM, Mandourah Y, Al-Hameed F, Sindi AA, Almekhlafi GA, Hussein MA, Saudi Critical Care Trial Group, et al. Corticosteroid therapy for critically ill patients with Middle East Respiratory syndrome. Am J Respir Crit Care Med. 2018;197(6):757-67. https://doi.org/10.1164/rccm.201706-1172OC.
24. Fang X, Mei Q, Yang T, Li L, Wang Y, Tong F, et al. Low-dose corticosteroid therapy does not delay viral clearance in patients with COVID-19. J Infect. 2020;81(1):147-78. https://doi.org/10. 1016/j.jinf.2020.03.039.

25. Spagnuolo V, Guffanti M, Galli L, Poli A, Querini PR, Ripa M, COVID-BioB study group, et al. Viral clearance after early corticosteroid treatment in patients with moderate or severe covid-19. Sci Rep. 2020;10(1):21291. https://doi.org/10.1038/s41598-02078039-1 (Erratum in: Sci Rep. 2021 May 17;11(1):10699).

26. Huang R, Zhu C, Jian W, Xue L, Li C, Yan X, et al. Corticosteroid therapy is associated with the delay of SARS-CoV-2 clearance in COVID-19 patients. Eur J Pharmacol. 2020;889:173556. https:// doi.org/10.1016/j.ejphar.2020.173556.

27. Li S, Hu Z, Song X. High-dose but not low-dose corticosteroids potentially delay viral shedding of patients with COVID-19. Clin Infect Dis. 2021;72(7):1297-8. https://doi.org/10.1093/cid/ciaa8 29.

28. Villar J, Ferrando C, Martínez D, Ambrós A, Muñoz T, Soler JA, et al. Dexamethasone in ARDS network. Dexamethasone treatment for the acute respiratory distress syndrome: a multicentre, randomised controlled trial. Lancet Respir Med. 2020;8(3):26776. https://doi.org/10.1016/S2213-2600(19)30417-5.

29. Bartoletti M, Marconi L, Scudeller L, Pancaldi L, Tedeschi S, Giannella M, PREDICO Study Group, et al. Efficacy of corticosteroid treatment for hospitalized patients with severe COVID-19: a multicenter study. Clin Microbiol Infect. 2021;27(1):105-11. https://doi.org/10.1016/j.cmi.2020.09.014.

30. López Zúñiga MÁ, Moreno-Moral A, Ocaña-Granados A, PadillaMoreno FA, Castillo-Fernández AM, Guillamón-Fernández D, et al. High-dose corticosteroid pulse therapy increases the survival rate in COVID-19 patients at risk of hyper-inflammatory response. PLoS ONE. 2021;16(1): e0243964. https://doi.org/10.1371/journ al.pone.0243964.PMID:33507958;PMCID:PMC7842890.

31. Vecchié A, Batticciotto A, Tangianu F, Bonaventura A, Pennella B, Abenante A, et al. High-dose dexamethasone treatment for COVID-19 severe acute respiratory distress syndrome: a retrospective study. Intern Emerg Med. 2021;16(7):1913-9. https:// doi.org/10.1007/s11739-021-02800-1.

32. Papamanoli A, Yoo J, Grewal P, Predun W, Hotelling J, Jacob $\mathrm{R}$, et al. High-dose methylprednisolone in nonintubated patients with severe COVID-19 pneumonia. Eur J Clin Invest. 2021;51(2):e13458. https://doi.org/10.1111/eci.13458 (Epub 2020 Dec 1).

33. Tromp K, van der Zee P, Rokx C, van Kampen J, Gommers D, Endeman $\mathrm{H}$. Effect of methylprednisolone on inflammation and coagulation in patients with severe COVID-19: a retrospective cohort study. Biomark Insights. 2021;4(16):11772719211021648. https://doi.org/10.1177/11772719211021647.

34. Climente-Martí M, Ruiz-Millo O, López-Cruz I, Atienza-García Á, Martínez-Moragón E, Garijo-Gómez E, Doctor Peset COVID19 Working Group, et al. Impact of intermediate to high doses of methylprednisolone on mortality rate in patients with COVID-19 pneumonia-indu. Int J Clin Pract. 2021;75(9):14479. https://doi. org/10.1111/ijcp.14479.

35. Pinzón MA, Ortiz S, Holguín H, Betancur JF, Cardona Arango D, Laniado H, et al. Dexamethasone vs methylprednisolone high dose for Covid-19 pneumonia. PLoS ONE. 2021;16(5): e0252057. https://doi.org/10.1371/journal.pone.0252057.

36. Solanich X, Antolí A, Padullés N, Fanlo-Maresma M, Iriarte A, Mitjavila F, et al. Pragmatic, open-label, single-center, randomized, phase II clinical trial to evaluate the efficacy and safety of methylprednisolone pulses and tacrolimus in patients with severe pneumonia secondary to COVID-19: the TACROVID trial protocol. Contemp Clin Trials Commun. 2021;21: 100716. https://doi. org/10.1016/j.conctc.2021.100716. 
37. Tomazini BM, Maia IS, Cavalcanti AB, Berwanger O, Rosa RG, Veiga VC, COALITION COVID-19 Brazil III Investigators, et al. Effect of dexamethasone on days alive and ventilator-free in patients with moderate or severe acute respiratory distress syndrome and COVID-19: the CoDEX randomized clinical trial. JAMA. 2020;324(13):1307-16. https://doi.org/10.1001/jama. 2020.17021

38. Fadel R, Morrison AR, Vahia A, Smith ZR, Chaudhry Z, Bhargava P, Henry Ford COVID-19 Management Task Force, et al. Early short-course corticosteroids in hospitalized patients with COVID-19. Clin Infect Dis. 2020;71(16):2114-20. https://doi.org/ 10.1093/cid/ciaa601.

39. Ko JJ, Wu C, Mehta N, Wald-Dickler N, Yang W, Qiao R. A Comparison of methylprednisolone and dexamethasone in intensive care patients with COVID-19. J Intensive Care Med. 2021;36(6):673-80. https://doi.org/10.1177/0885066621994057.

40. Ranjbar K, Moghadami M, Mirahmadizadeh A, Fallahi MJ, Khaloo V, Shahriarirad R, et al. Methylprednisolone or dexamethasone, which one is superior corticosteroid in the treatment of hospitalized COVID-19 patients: a triple-blinded randomized controlled trial. BMC Infect Dis. 2021;21(1):337. https://doi.org/ 10.1186/s12879-021-06045-3.

41. Angus DC, Derde L, Al-Beidh F, Annane D, Arabi Y, Beane A, et al. Effect of hydrocortisone on mortality and organ support in patients with severe COVID-19: the REMAP-CAP COVID19 corticosteroid domain randomized clinical trial. JAMA. 2020;324(13):1317-29. https://doi.org/10.1001/jama.2020.17022.

42. Garcia-Vidal C, Sanjuan G, Moreno-García E, Puerta-Alcalde P, Garcia-Pouton N, Chumbita M, COVID-19 Researchers Group, et al. Incidence of co-infections and superinfections in hospitalized patients with COVID-19: a retrospective cohort study. Clin Microbiol Infect. 2021;27(1):83-8. https://doi.org/10.1016/j.cmi. 2020.07.041.

43. Tamez-Pérez HE, Quintanilla-Flores DL, Rodríguez-Gutiérrez R, González-González JG, Tamez-Peña AL. Steroid hyperglycemia: prevalence, early detection and therapeutic recommendations: a narrative review. World J Diabetes. 2015;6(8):1073-81. https:// doi.org/10.4239/wjd.v6.i8.1073.

44. Coronavirus Disease 2019 (COVID-19) Treatment Guidelines. National Institutes of Health. 2021. https://www.covid19treatmen tguidelines.nih.gov/. Accessed 14 Oct 2021.

45. - Bhimraj A, Morgan RL, Shumaker AH, Lavergne V, Baden L, Cheng VC et al. Infectious diseases society of America guidelines on the treatment and management of patients with COVID-19. Infectious Diseases Society of America 2021; Version 5.3.1. 2021. https://www.idsociety.org/practice-guideline/covid-19-guidelinetreatment-and-management/. Accessed 14 Oct 2021.

46. Mozaffari E, Chandak A, Zhang Z, Liang S, Thrun M, Gottlieb $\mathrm{RL}$, et al. Remdesivir treatment in hospitalized patients with COVID-19: a comparative analysis of in-hospital all-cause mortality in a large multi-center observational cohort. Clin Infect Dis. 2021;2021:ciab875. https://doi.org/10.1093/cid/ciab875.

47. Ader F, Bouscambert-Duchamp M, Hites M, Peiffer-Smadja N, Poissy J, Belhadi D, DisCoVeRy Study Group, et al. Remdesivir plus standard of care versus standard of care alone for the treatment of patients admitted to hospital with COVID-19 (DisCoVeRy): a phase 3, randomised, controlled, open-label trial. Lancet Infect Dis. 2021. https://doi.org/10.1016/S1473-3099(21)00485-0.

48. Bell ML, Kenward MG, Fairclough DL, Horton NJ. Differential dropout and bias in randomised controlled trials: when it matters and when it may not. BMJ. 2013;21(346): e8668. https://doi.org/ 10.1136/bmj.e8668.

Publisher's Note Springer Nature remains neutral with regard to jurisdictional claims in published maps and institutional affiliations. 